\title{
Tributyltin (TBT): A Review on Microbial Resistance and Degradation
}

\author{
ANDREIA CRUZ, ${ }^{1}$ ANA MARIA ANSELMO,${ }^{2}$ SATORU SUZUKI, ${ }^{3}$ \\ and SÓNIA MENDO ${ }^{1}$ \\ ${ }^{1}$ Departamento de Biologia \& CESAM, Universidade de Aveiro, Aveiro, Portugal \\ ${ }^{2}$ Laboratório Nacional de Energia e Geologia, Unidade de Bioenergia, Estrada da Portela, \\ Bairro do Zambujal, Amadora, Portugal \\ ${ }^{3}$ Centre for Marine Environmental Studies (CMES), Ehime University, Matsuyama, Japan
}

\begin{abstract}
Tributyltin (TBT) is one of the most toxic xenobiotics ubiquitous in the aquatic environment. Several reports have described the negative impact of TBT in living organisms, from bacteria to mammals. Over the world, TBT contamination has being described as a serious problem. Thus, it is imperative to decontaminate TBT polluted sites. Bioremediation strategies may constitute an alternative to conventional decontamination methods, benefiting from the microorganisms potential to metabolize xenobiotics. Several microorganisms among bacteria, fungus, and algae have been reported to possess the ability to resist and, in certain cases, degrade TBT in their simple and less toxic derivatives. Due their characteristics, some of those microorganisms have been used for bioremediation studies and to construct bioreporters to detect TBT in the environment. This review provides an overview regarding microbial TBT resistance, while focusing on TBT degradation and bioremediation. A comprehensive revision on the several applications of organotin compounds, adverse biological effects on living organisms, and information regarding the available TBT bioreporters is also included.
\end{abstract}

KEY WORDS: tributyltin, resistance, degradation, microbial bioremediation, bioreporter

Address correspondence to Andreia Cruz, Departamento de Biologia \& CESAM, Universidade de Aveiro, Campus de Santiago, 3810-193, Aveiro, Portugal. E-mail: andreia.cruz@ua.pt 